\title{
A mouse model of human oral-esophageal cancer
}

\author{
Oliver G. Opitz, ${ }^{1,2,3}$ Hideki Harada, ${ }^{1,2}$ Yasir Suliman, ${ }^{1,2}$ Ben Rhoades, ${ }^{1,2}$ \\ Norman E. Sharpless, ${ }^{4}$ Ralph Kent, ${ }^{5}$ Levy Kopelovich, ${ }^{6}$ Hiroshi Nakagawa, ${ }^{1,2}$ \\ and Anil K. Rustgi 1,2,7,8 \\ ${ }^{1}$ Division of Gastroenterology, and \\ ${ }^{2}$ Abramson Family Cancer Research Institute, University of Pennsylvania, Philadelphia, Pennsylvania, USA \\ ${ }^{3}$ Department of Medicine, University of Freiburg, Freiburg, Germany \\ ${ }^{4}$ Dana Farber Cancer Institute, Harvard Medical School, Boston, Massachusetts, USA \\ ${ }^{5}$ Forsyth Dental Center and Harvard School of Dental Medicine, Boston, Massachusetts, USA \\ ${ }^{6}$ Division of Cancer Prevention, National Cancer Institute, Bethesda, Maryland, USA \\ ${ }^{7}$ Department of Genetics, and \\ ${ }^{8}$ Abramson Cancer Center, University of Pennsylvania, Philadelphia, Pennsylvania, USA
}

Squamous cancers of the oral cavity and esophagus are common worldwide, but no good genetically based animal model exists. A number of environmental factors as well as genetic alterations have been identified in these cancers, yet the specific combination of genetic events required for cancer progression remains unknown. The Epstein-Barr virus ED-L2 promoter (L2) can be used to target genes in a specific fashion to the oral-esophageal squamous epithelium. To that end, we generated L2-cyclin D1 $\left(\mathrm{L} 2 \mathrm{D}^{+}\right)$mice and crossbred these with $\mathrm{p} 53$-deficient mice. Whereas $\mathrm{L} 2 \mathrm{D} 1^{+}$mice exhibit a histologic phenotype of oral-esophageal dysplasia, the combination of cyclin D1 expression and p53 deficiency results in invasive oral-esophageal cancer. The development of the precancerous lesions was significantly reversed by the application of sulindac in the drinking water of the $\mathrm{L} 2 \mathrm{D} 11^{+} / \mathrm{p} 53^{+/-}$mice. Furthermore, cell lines derived from oral epithelia of $\mathrm{L} 2 \mathrm{D} 1^{+} / \mathrm{p} 53^{+/-}$and $\mathrm{L} 2 \mathrm{D} 1^{+} / \mathrm{p} 53^{-/}$mice, but not control mice, formed tumors in athymic nude mice. These data demonstrate that $\mathrm{L} 2 \mathrm{D} 1^{+} / \mathrm{p} 53^{+/-}$mice provide a well-defined, novel, and faithful model of oral-esophageal cancer, which allows for the testing of novel chemopreventive, diagnostic, and therapeutic approaches.

$$
\text { J. Clin. Invest. 110:761-769 (2002). doi:10.1172/JCI200215324. }
$$

\section{Introduction}

Squamous cancers arising in the oral cavity and esophagus are common worldwide. Approximately 40,000 new cases of oral squamous cell cancer occur annually in the United States, making it the sixth most common cancer in the general population (1). Furthermore, with nearly 350,000 cases each year, it is the third most common cancer in developing nations (1). The prognosis for oral cancer remains dismal, as about $50 \%$ of patients succumb to the disease and its complications within five years of diagnosis. Esophageal squamous cell cancer is among the ten most common cancers in the United States and the fifth most common among males worldwide (2). Patients suffer from a poor prognosis when presenting at advanced stages. While there are a few classic animal models using chemical carcinogens to induce oral squamous cell

Received for publication February 21, 2002, and accepted in revised form July 16, 2002.

Address correspondence to: Anil K. Rustgi, University of Pennsylvania, 415 Curie Boulevard, Philadelphia, Pennsylvania 19104-2144, USA. Phone: (215) 898-0154; Fax: (215) 573-5412; E-mail: anil2@mail.med.upenn.edu.

Hideki Harada and Yasir Suliman contributed equally to this work.

Conflict of interest: No conflict of interest has been declared. Nonstandard abbreviations used: Epstein-Barr virus ED-L2 promoter (L2). cancer $(3,4)$ and esophageal squamous cell cancer $(5)$, no suitable genetically defined model exists in which to study progression of this disease.

Cyclin D1 expression is a frequent genetic event in the vast majority of oral and esophageal squamous cell cancers. It occurs either through gene amplification or mitogen induction of cyclin D1 transcription, indicating a critical role for cyclin D1 in these cancers $(6,7)$. Since nuclear accumulation of the cyclin D1 protein has been observed in precancerous dysplastic lesions (8-10), cyclin D1 expression is believed to be an early event in oral and esophageal squamous cell carcinogenesis. Additionally, p53 mutations are frequently found in the majority of oral and esophageal squamous cell cancers $(11,12)$, and their biological consequences are several, including promoting cell cycle progression, augmenting genomic instability, and decreasing growth arrest in response to genotoxic stress $(13,14)$.

While other genetic alterations - for example, p16 inactivation, EGF-R gene amplification, and c-myc amplification - have been described in human oral and esophageal squamous cell cancers, it is apparent that cyclin D1 expression and p53 inactivation represent the most frequent known genetic alterations. However, the timing and sequence of the genetic alterations that are important in oral and esophageal carcinogenesis require elucidation. Therefore, we have developed a well-defined genetic model of oral-esophageal 
carcinogenesis. In this model, we express cyclin D1 specifically in the oral-esophageal squamous epithelia of transgenic mice using the Epstein-Barr virus ED-L2 promoter (L2), generating $\mathrm{L} 2 \mathrm{D} 1^{+}$mice $(15)$. When

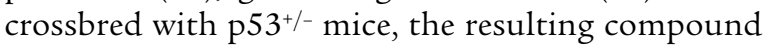
mice reveal histologic evidence of invasive oralesophageal squamous cell cancer. Cell lines derived from the oral epithelia of the compound mice $\left(\mathrm{L} 2 \mathrm{D} 1^{+} / \mathrm{p} 53^{+/-}\right.$or $\left.\mathrm{L} 2 \mathrm{D} 1^{+} / \mathrm{p} 53^{-/-}\right)$, but not cell lines from control mice, induce tumor formation in athymic nude mice. Because this well-characterized mouse tumor model phenocopies the human disease, we believe it will permit the identification of cooperating genetic alterations as well as testing novel chemopreventive and therapeutic agents.

\section{Methods}

Generation of transgenic mice. L2 was fused to human cyclin D1 cDNA to create a transgene from which founder lines were generated. This transgene was microinjected into the male pronucleus of single-cell embryos isolated from pregnant, superovulated D3/C57BL/ 6 females. Fertilized eggs were reimplanted in the oviducts of $\mathrm{Sw}(\mathrm{fbr})$ foster females that had been previously mated with vasectomized $\mathrm{Sw}(\mathrm{fbr})$ males. Potential founders were screened by Southern blot and PCR analyses, and founder lines were identified. Transgenic mice were backcrossed over three generations to the C57BL/6 strain to yield a greater than $90 \%$ C57BL/6 background for analysis. This particular strain was chosen for its enhanced tendency for tumorigenesis. The mice were backcrossed into the same background of p53 heterozygous mice (B6.129S2Trp53tm1Tyj, former name C57BL/6J-Trp53tm1Tyj) that were purchased from The Jackson Laboratory (Bar Harbor, Maine, USA). Then cyclin D1-expressing mice were crossbred with $\mathrm{p} 53^{+/-}$mice to generate these genotypes: $\mathrm{L} 2 \mathrm{D} 1^{+} / \mathrm{p} 53^{+/-}$(expressing low, moderate, or high cyclin D1); $\mathrm{L} 2 \mathrm{D} 1^{+} / \mathrm{p} 53^{-/-}$(expressing low, moderate, or high cyclin D1); L2D1 $/ \mathrm{p}^{+} 3^{+/+}$(expressing low, moderate, or high cyclin D1); L2D1-/p53"/-; L2D1-/p53-/-; and L2D1- $/ \mathrm{p} 53^{+/+}$(wild-type).

In a subgroup of eight additional wild-type and eight $\mathrm{L} 2 \mathrm{D} 1^{+} / \mathrm{p} 53^{+/-}$littermates, the drinking water was supplemented with $400 \mathrm{ppm}$ sulindac on a daily basis for 3 months (starting when all mice were 4 months of age) to test the potential chemopreventive efficacy of this agent. Mice were sacrificed 1 month after completion of the treatment. Dose was based on a limited pilot study using 200 ppm sulindac.

$P C R$ and Southern blot genotyping. Genotyping of cyclin D1 and P53 was done using PCR and was confirmed by Southern blot analysis. Mice were genotyped initially for the human cyclin D1 gene using a PCR-based strategy. Specific primers for L2 (L2-S7 and L2-AS2) were used to generate an amplified product of $300 \mathrm{bp}$ in the transgene. ${\mathrm{L} 2 \mathrm{D} 1^{+}}^{+}$mice were additionally genotyped by Southern blot analysis with an $\mathrm{L} 2$ probe from the transgene promoter. $\mathrm{p} 53$ genotyping was done with a PCR strategy. Two sets of primers were used, one specific for the neomycin cassette and the other for exon 6 (targeted) of the p53 gene. The amplified neomycin product was $300 \mathrm{bp}$, and the amplified p53 product was $600 \mathrm{bp}$. Thus, wild-type $\mathrm{p} 53$ yielded a 600-bp amplified product, $\mathrm{p} 53^{+/-}$yields $600-\mathrm{bp}$ and $300-\mathrm{bp}$ amplified products, and $\mathrm{p} 53^{-/-}$yields only a 300-bp amplified product.

Northern blot analysis and kinase assay. Northern blot analysis was done as described previously (7). Briefly, total RNA was purified. RNA samples $(10 \mu \mathrm{g})$ were fractionated and transferred onto a Hybond N nylon membrane (Amersham Corp., Burlington, Massachusetts, USA). The ultraviolet-cross-linked membrane was hybridized with a 1.4-kb cyclin D1 cDNA random primer labeled with $\left[\alpha-{ }^{32} \mathrm{P}\right] \mathrm{dCTP}$ (NEN Life Science Products Inc., Boston, Massachusetts, USA) and washed under high-stringency conditions.

Kinase assays were performed as described (16). Briefly, cell lysates were sonicated and protein concentration was determined. Lysates were then incubated with either Cdk4 or Cdk6 antibody (Santa Cruz Biotechnology Inc., Santa Cruz, California, USA) at $4^{\circ} \mathrm{C}$. Thirty microliters of Sepharose beads were added. The kinase reaction contained beads, kinase reaction buffer, $1 \mathrm{mM}$ ATP, $1 \mathrm{mM}$ DTT, $10 \mu \mathrm{Ci}$ of $\left[\gamma^{-32} \mathrm{P}\right] \mathrm{ATP}$, and carboxyl-terminal fragment of the retinoblastoma protein fused to glutathione $S$ transferase (GST-pRb, a gift of P. Hinds, Harvard Medical School, Boston, Massachusetts, USA) and histone $\mathrm{H} 1$ as substrates. Kinase assays were performed for 45 minutes at $37^{\circ} \mathrm{C}$. The samples were electrophoresed on a $12.5 \%$ SDSpolyacrylamide gel.

Histology and immunohistochemistry. Total autopsies were done on all transgenic and control mice. All comparisons were made between tissue sections of agematched wild-type and transgenic mice. The tissue sections were separated into four categories: mouth (buccal mucosa), tongue (tip, center and floor), upper esophagus, and lower esophagus (including the squamous forestomach). Tissues were extracted, fixed in $4 \%$ paraformaldehyde, embedded in paraffin, and processed for hematoxylin and eosin staining.

All histologic changes were assessed and scored independently in a blinded fashion by three different observers. Dysplasia was defined as the presence of unequivocally neoplastic squamous cells that replaced a variable proportion of normal epithelium. It is characterized by an accumulation of atypical cells with nuclear hyperchromasia, abnormally clumped chromatin, and pleomorphism. The cells have an increased nucleus/cytoplasm ratio and exhibit a loss of polarity and increased mitosis. Dysplasia was graded by the degree of changes in the tissues: 0 , normal; 1 , mild dysplasia; 2 , moderate dysplasia; 3 , severe dysplasia with or without invasive cancer. Dysplasia scores were compared by the Fisher exact test, progression of dysplasia and cancer with age by the Mantel-Haenszel $\chi^{2}$ test, and cancer occurrence in oral and esophageal tissues by the marginal homogeneity test. In all cases, $P<0.05$ was considered to be significant. 

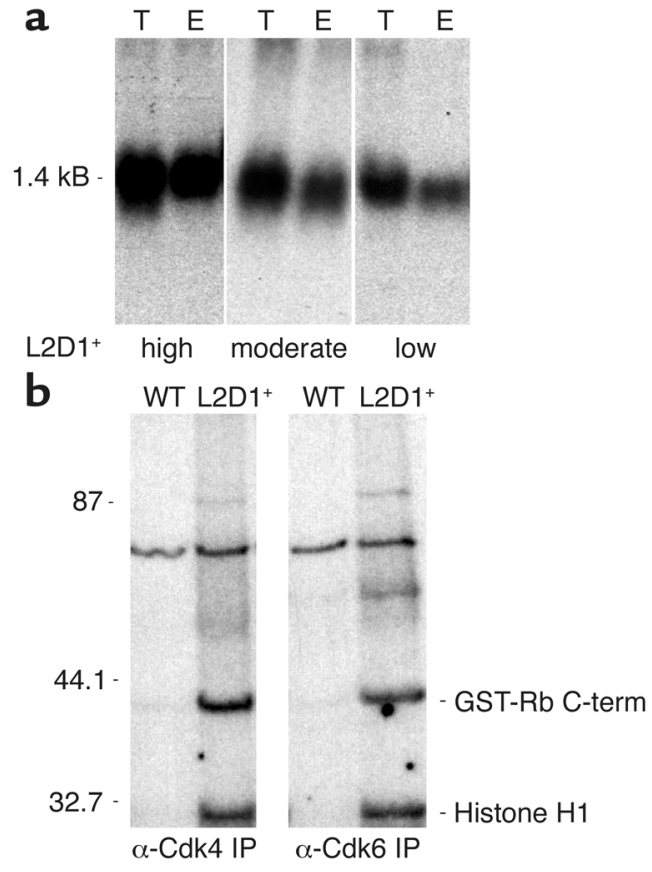

For immunohistochemistry, six-micrometer sections of paraffin-embedded, formalin-fixed tissue were dewaxed and rehydrated with a series of graded ethanols. Antigenicity was restored using standard microwave retrieval methods. Endogenous peroxidase activity was quenched by treatment with $1.5 \%$ hydrogen peroxide. Endogenous biotin was quenched with an avidin-biotin blocking kit (Vector Laboratories Inc., Burlingame, California, USA), and tissue was blocked using Protein Blocking Solution (Coulter Immunotech, Marseilles, France). Primary antibodies were diluted in PBT $(1 \times$ PBS with $0.1 \%$ BSA and $0.2 \%$ Triton X-100) as follows: mouse anti-pancytokeratin (1:3,000; Sigma-Aldrich, St. Louis, Missouri, USA), mouse anti-desmin (1:1,000; Sigma-Aldrich), rabbit anti-S100 (1:1,000; Novacastra Laboratories Ltd., Newcastle upon Tyne, United Kingdom), rabbit anti-COX2 (1:1,000; Cayman Chemical Co., Ann Arbor, Michigan, USA), and rabbit anti-EP-2 (1:500; Cayman Chemical Co.). Sections were incubated with primary antibodies overnight at $4^{\circ} \mathrm{C}$ followed by incubation with appropriate biotinylated secondary antibodies (Vector Laboratories Inc.) using the ABC Elite kit

\section{Figure 1}

(a) Northern blot analysis with a random-primed, ${ }^{32} \mathrm{P}$-labeled human cyclin D1 cDNA probe in three different founder lines with low, moderate, and high cyclin D1 expression in tongue ( $T$ ) and esophageal (E) tissues. (b) Tongue and esophageal epithelial protein extracts from mice expressing moderate levels of cyclin D1 were immunoprecipitated with Cdk4 or Cdk6 antibody. After a kinase reaction with $[\gamma-32$ P]ATP and GST-retinoblastoma carboxyl-terminus substrate (GST-Rb c-term) or histone $\mathrm{H} 1$ substrate, products were electrophoresed on a $12.5 \%$ SDS-polyacrylamide gel.

(Vector Laboratories Inc.). Antibody binding was visualized using a DAB kit (Vector Laboratories Inc.).

Slot blot and methylation PCR analysis. Slot blots for p16 $16^{\text {INK4a }}$ and p19ARF loss of heterozygosity, and EGF-R amplification (17) and methylation-specific PCR for $\mathrm{p} 16^{\text {INK4a }}(18)$ were performed as described previously. Mouse EGF-R cDNA was labeled by random priming (gift of R. DePinho, Dana Farber Cancer Institute).

Generation of cell lines. Mouse oral and esophageal keratinocytes were isolated from tongue and esophageal tissues dissected from different genotypes. The tongue and esophagus were slit open longitudinally and cut into three and two pieces, respectively. Each piece of tissue was digested with 1 unit $/ \mathrm{ml}$ dispase (Roche Molecular Biochemicals, Mannheim, Germany) at $4^{\circ} \mathrm{C}$ overnight to separate the mucosal epithelium. The epithelium was minced finely and incubated at $37^{\circ} \mathrm{C}$ in trypsin-EDTA (Invitrogen Corp., San Diego, California, USA) for 5 minutes. Following incubation, soybean trypsin inhibitor (Sigma-Aldrich) was added to terminate trypsin activity, and cells were centrifuged at $160 \mathrm{~g}$ for 5 minutes. The cell pellets were resuspended in keratinocyte-SFM without calcium chloride (Invitrogen Corp.) supplemented with $45 \mathrm{mg} / \mathrm{ml}$ bovine pituitary extract (Invitrogen Corp.), $1 \mathrm{ng} / \mathrm{ml}$ recombinant EGF (Invitrogen Corp.), $0.018 \mathrm{mM}$ calcium chloride (Clonetics Corp., San Diego, California, USA), 100 units $/ \mathrm{ml}$ penicillin, $100 \mu \mathrm{g} / \mathrm{ml}$ streptomycin, $5 \mu \mathrm{g} / \mathrm{ml}$ gentamicin, and 100 units $/ \mathrm{ml}$ nystatin. Cultures were grown at $37^{\circ} \mathrm{C}$ and $5 \% \mathrm{CO}_{2}$, and the medium was exchanged every 2 days. After 7 days of primary culture, the cells were maintained in medium without gentamicin and nystatin. When the cells reached $60-70 \%$ confluence, they were passaged.

Tumorigenicity assays. Cells were harvested by trypsinization, washed, and resuspended in $200 \mu \mathrm{l}$ of

Table 1

Number of mice generated and sacrificed by genotype and sacrifice timepoint

\begin{tabular}{|c|c|c|c|c|c|c|}
\hline & $\mathrm{L}^{2} \mathrm{D} 1^{+} / \mathrm{p} 53^{+/-}$ & $\mathrm{L} 2 \mathrm{D} 1^{+} / \mathrm{p} 53^{+/+}$ & WT/WT & $\mathrm{WT} / \mathrm{p} 53^{+/-}$ & $\mathrm{L}^{2 \mathrm{D}} 1^{+} / \mathrm{p} 53^{-/-}$ & $\mathrm{WT} / \mathrm{p} 53^{-/-}$ \\
\hline 3 months & 25 & 10 & 8 & 8 & NA & NA \\
\hline 5 months & NA & NA & NA & NA & 30 & 12 \\
\hline 6 months & 28 & 12 & 11 & 11 & NA & NA \\
\hline 12 months & 31 & 19 & 8 & 12 & NA & NA \\
\hline Total & 84 & 41 & 27 & 31 & 30 & 12 \\
\hline
\end{tabular}

All L2D1+ groups consist of an equal number of low, moderate, and high expressors of the cyclin D1 transgene. NA, not applicable. 

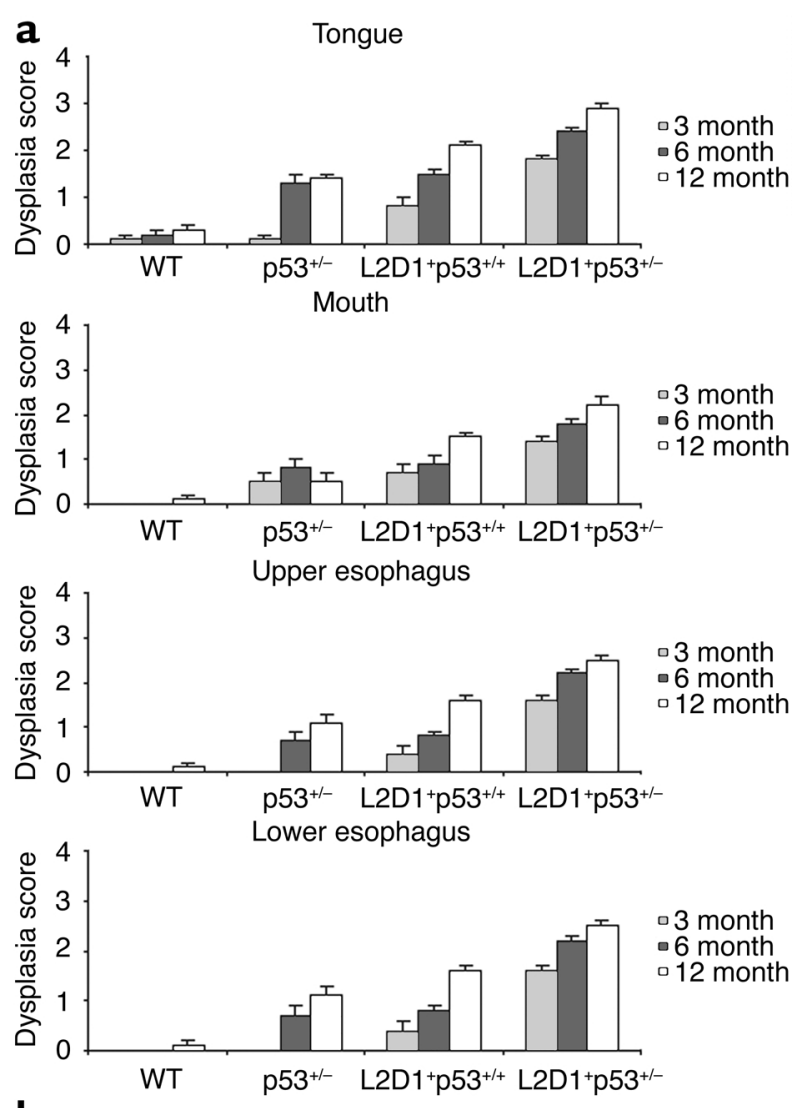

b

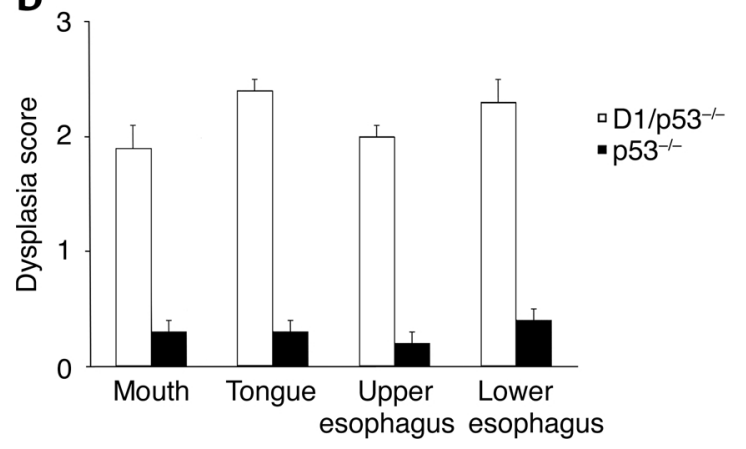

keratinocyte-SFM containing India ink. Five- to sevenweek old athymic nude mice (NIH III; Charles River Laboratories Inc., Wilmington, Massachusetts, USA) were injected with a cell suspension containing $5 \times 10^{6}$

\section{Figure 2}

Dysplasia scores are depicted for wild-type, p53+/-, L2D $1^{+} / \mathrm{p} 53^{+/+}$, and $\mathrm{L} 2 \mathrm{D} 1^{+} / \mathrm{p} 53^{+/-}$mice for tongue, mouth, upper esophagus, and lower esophagus tissues at 3,6 , and 12 months (a). The same scoring system is represented for $\mathrm{L} 2 \mathrm{D} 1^{+} / \mathrm{p} 53^{-/-}$and $\mathrm{p} 53^{-/-}$mice at 5 months $(\mathbf{b})$. Scores for the $\mathrm{L} 2 \mathrm{D} 1^{+} / \mathrm{p} 53^{+/-}$group were significantly different from control scores at 6 and 12 months. Scores for the $\mathrm{L} 2 \mathrm{D} 1^{+} / \mathrm{p} 53^{-/-}$mice were significantly different from controls at 5 months. $P<0.05$. WT, wild-type.

exponentially growing cultured oral keratinocytes from the different genotypes. Tumor size was measured on a regular basis. The time of initial tumor formation was defined as the time when the tumor reached a diameter of $3 \mathrm{~mm}$. Mice were sacrificed after 12 weeks of monitoring. Each tumor was dissected, measured, and fixed in 4\% paraformaldehyde for histological analysis.

The murine genomic DNA fragment (from M. Meyerson, Dana Farber Cancer Institute), EGF-R transgenic mouse (from R. DePinho, Dana Farber Cancer Institute), and Sp6 lung cancer cells (from T. Devereux, National Institute of Environmental Health Sciences, Research Triangle Park, North Carolina) were all donated gifts.

\section{Results}

The Epstein-Barr virus lytically infects human oralpharyngeal squamous mucosa. We have previously identified an Epstein-Barr virus promoter, ED-L2 (designated L2), that can target genes in oralesophageal squamous epithelial cells. There is regulation of the L2 promoter by the interplay of key cis-regulatory elements and members of the KLF transcription factor family (19).

We targeted human cyclin D1 cDNA to the oralesophageal epithelia using this promoter. Since the level of cyclin D1 expression may be critical for its oncogenic potential (20), we generated founder mice with varying cyclin D1 expression in the oral-esophageal squamous epithelium. Mice expressing low, moderate, and high levels of cyclin D1 were generated, corresponding to three-, five-, and eightfold elevations of ectopic (human) cyclin D1 RNA levels, respectively (Figure 1). Furthermore, kinase assays revealed that ectopic cyclin D1 from either the oral or esophageal epithelium

Table 2

Cancer incidence

\begin{tabular}{|c|c|c|c|c|c|}
\hline & & $\mathrm{L}^{2} \mathrm{D} 1^{+} / \mathrm{p} 53^{+/+}$ & $\mathrm{L}^{2} \mathrm{D} 1^{+} / \mathrm{p} 53^{+/-}$ & WT/WT & $\mathrm{WT} / \mathrm{p} 53^{+/-}$ \\
\hline \multirow[t]{2}{*}{3 months } & $\%$ & 0 & 12 & 0 & 0 \\
\hline & $(x /$ tot $)$ & $0 / 10$ & $3 / 25$ & $0 / 8$ & $0 / 8$ \\
\hline \multirow[t]{2}{*}{6 months } & $\%$ & 0 & 32 & 0 & 0 \\
\hline & $(\mathrm{x} / \mathrm{tot})$ & $0 / 12$ & $9 / 28$ & $0 / 11$ & $0 / 11$ \\
\hline \multirow[t]{2}{*}{12 months } & $\%$ & 0 & 61 & 0 & 8 \\
\hline & $(\mathrm{x} / \mathrm{tot})$ & $0 / 19$ & $19 / 31$ & $0 / 8$ & $1 / 12$ \\
\hline
\end{tabular}

Number of L2D1 ${ }^{+} / \mathrm{p} 53^{+/-}$mice with cancer of the mouth (buccal mucosa), tongue, upper esophagus, or lower esophagus at different timepoints compared to control mice. For cancer occurrence over time, at 3 months $P>0.05 ; 6$ months, $P=0.006$, and at 12 months, $P<0.001$ (Fisher exact test). $P<0.001$ (Mantel-Haenszel $\chi^{2}=14.6$ ) for progression with age in $\mathrm{L} 2 \mathrm{D} 1^{+} / \mathrm{p} 53^{+/-}$mice. 

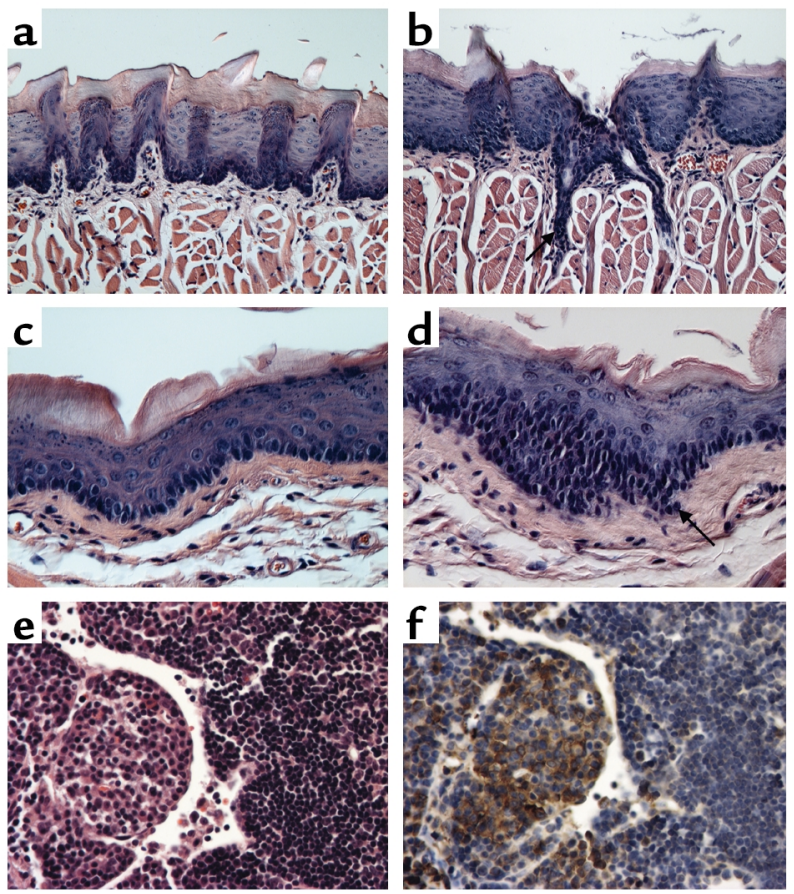

Figure 3

Hematoxylin and eosin staining of tongue ( $\mathbf{a}$ and $\mathbf{b}$ ) and esophagus (c and d). (a and c) Wild-type mouse at 12 months of age. (b and d) L2D $1^{+} / \mathrm{p} 53^{+/-}$mouse at 12 months of age. $\mathbf{b}$ and $\mathbf{d}$ show evidence of nuclear atypia, enlargement, and hyperchromasia of cells as well as loss of polarity with migration of atypical cells into intermediate and superficial layers as cellular and histologic features of dysplasia. In particular, there is invasion of malignant cells into the submucosa and muscle of the tongue and into the submucosa of the esophagus. Cancer lesions are marked by arrows. (e) Hematoxylin and eosin staining and (f) pancytokeratin immunohistochemistry from one representative paraesophageal lymph node metastasis. There are keratin-positive epithelial cells within the lymphatic tissue. Magnification, $\times 400$.

forms an immune complex with either Cdk4 or Cdk6, resulting in phosphorylation of the retinoblastoma protein (Figure 1). These three founder lines were selected for further breeding and were backcrossed to the C57BL/6 background.

We then bred cyclin D1 transgenic mice with p53-deficient C57BL/6 mice $(21,22)$ to yield the desired $\mathrm{L} 2 \mathrm{D} 1^{+} / \mathrm{p} 53^{+/-}$and $\mathrm{L} 2 \mathrm{D} 1^{+} / \mathrm{p} 53^{-/-}$genotypes. Littermate control mice were generated with the following genotypes: wild-type; high, moderate, and low cyclin D1

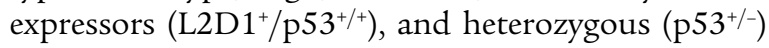
and homozygous $\left(\mathrm{p} 53^{-/-}\right) \mathrm{p} 53$-deficient mice with normal (mouse) cyclin D1 levels (Table 1). All mice were monitored for appearance and weight, and were sacrificed at designated timepoints for determination of histological changes, primarily in the oral cavity and esophagus. We confirmed that oral-esophageal tissue-specific cyclin D1 expression resulted in mild to severe dysplasia over time. Moderate to severe dysplasia developed by 12 months of age, but without leading to cancer.

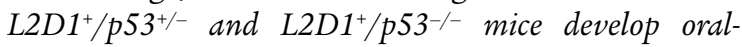
esophageal cancer. $\mathrm{L} 2 \mathrm{D} 1^{+} / \mathrm{p} 53^{+/-}$and $\mathrm{L} 2 \mathrm{D} 1^{+} / \mathrm{p} 53^{-/}$mice developed histologic evidence of severe oral-esophageal squamous epithelial dysplasia and even cancer by 5 and 6 months of age, respectively. These represented statistically significant changes compared with all control groups (Figure 2). It should be emphasized that $\mathrm{p} 53^{-/}$ and $\mathrm{L} 2 \mathrm{D} 1^{+} / \mathrm{p} 53^{-/-}$mice could not be analyzed beyond 5 months due to morbidity from systemic lymphomas or sarcomas and resulting death $(15,16)$.

The $\mathrm{L} 2 \mathrm{D} 1^{+} / \mathrm{p} 53^{+/-}$mice were followed to 12 months of age and displayed histologic evidence of cancer in the oral cavity (anterior and posterior tongue, buccal mucosa) and esophagus (upper and lower esophagus), with invasion into the submucosa, muscle, and blood vessels (Figure 3). Approximately $25 \%$ of cancers had evidence of metastasis to lymph nodes, which was confirmed by pancytokeratin staining (Figure 3 , e and $\mathrm{f}$ ). Enlarged lymph nodes were observed mostly in the paratracheo-pharyngeal-esophageal regions. Enlarged lymph nodes were not found in the control mice. Notably, $\mathrm{L} 2 \mathrm{D} 1^{+} / \mathrm{p} 53^{+/}$mice showed an increase in cancer frequency with time, from 3 months to 12 months, with $61 \%$ of animals affected at 12 months (Tables 2 and 3 ). The progression with age was significant by a test for trend $\left(P<0.001\right.$; Mantel-Haenszel $\left.\chi^{2}=14.6\right)$. Interestingly, the occurrence of cancer was significantly different among the tissues types $(P=0.02$ for marginal homogeneity tests), with the tongue most affected compared with buccal mucosa and esophagus (Tables 2 and 3 ).

The occurrence of cancer in the $\mathrm{L} 2 \mathrm{D} 1^{+} / \mathrm{p} 53^{+/-}$mice at 6 and 12 months was statistically significant compared with the control groups $(P<0.05$, Fisher exact test). It is likely that $\mathrm{L} 2 \mathrm{D} 1^{+} / \mathrm{p} 53^{-/-}$mice, while displaying cancer at 5 months, would have had a higher frequency of cancer with a longer life span. Our study also allowed examination of the percentage of $\mathrm{L} 2 \mathrm{D} 1^{+} / \mathrm{p} 53^{+/-}$mice with cancer at one or more tissue sites according to cyclin D1 levels. However, we found no association between the percentage of affected animals and cyclin D1 levels. The number of affected animals with cancer combining all timepoints was 10 of 29 mice expressing low levels of cyclin D1, 12 of 29 in mice with moderate expression, and 9 of 26 in mice expressing high levels of cyclin D1. The differences were not significant $\left(P=0.976\right.$; Mantel-Haenszel $\left.\chi^{2}, P=0.001\right)$.

p16 INK4a, $p 19^{A R F}$, and EGF-R are not altered in $L 2 D 1^{+} / p 53^{+/-}$mice. In order to determine whether cyclin D1 expression and p53 deficiency were sufficient by

\section{Table 3}

Number of $\mathrm{L} 2 \mathrm{D} 11^{+} / \mathrm{p} 53^{+/-}$mice with cancer of the mouth (buccal mucosa), tongue, upper esophagus, or lower esophagus analyzed by affected tissue

\begin{tabular}{lcccc}
\hline Mouth & Tongue & $\begin{array}{c}\text { Upper } \\
\text { esophagus }\end{array}$ & $\begin{array}{c}\text { Lower } \\
\text { esophagus }\end{array}$ \\
$\%$ & 12.5 & 25.3 & 11.0 & 12.7 \\
X/tot & $10 / 80$ & $21 / 83$ & $9 / 82$ & $10 / 79$ \\
\hline
\end{tabular}

Cancer occurrence is different among the four tissues types based on 75 mice $(P=0.02$ for marginal homogeneity test $)$. 


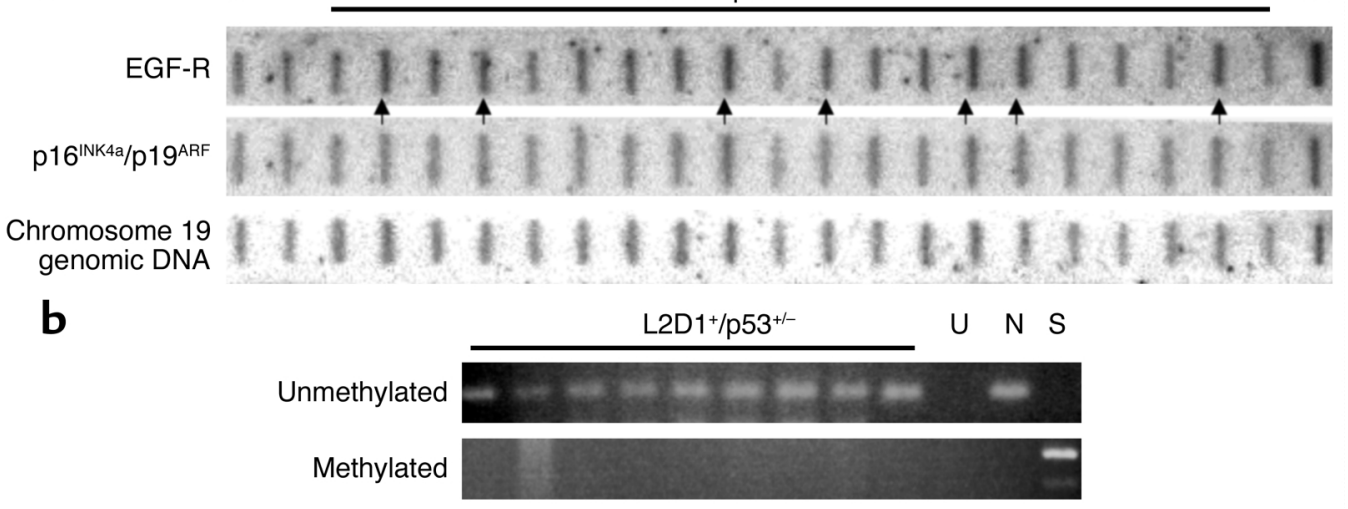

Figure 4

(a) Slot blots of mouse EGF-R cDNA, exon $1 \alpha$ fragment for p16 INK4a/p19ARF, and a nonamplified chromosome 19 murine genomic DNA fragment. Of note, there is a mild increase in EGF-R cDNA in some samples (arrows). C, WT/WT; TG, EGF-R transgenic mouse. (b) Methylation-specific PCR for p16 ${ }^{\text {INK4a }}$. No p16 $16^{\text {INK4a }}$ promoter methylation was observed in 9 informative samples. Sp 6 lung cancer cells were used as a positive control. $U$, uninformative; $N$, normal; S, Sp6 lung.

themselves to induce cancer in the oral and esophageal tissues, we tested whether other known genetic alterations were acquired in the process of oral-esophageal carcinogenesis. When comparing DNA isolated from cancerous cells from 12 -month-old $\mathrm{L} 2 \mathrm{D} 1^{+} / \mathrm{p} 53^{+/-}$mice with those of age-matched wild-type littermates, there was no evidence of $\mathrm{p} 16^{\mathrm{INK} 4 \mathrm{a}}$ or $\mathrm{p} 19^{\mathrm{ARF}}$ deletion, or p16 ${ }^{\mathrm{INK} 4 \mathrm{a}}$ promoter hypermethylation (Figure 4). There was minimal EGF-R gene amplification (fold increase of 1.5-2) in some transgenic mice compared with wildtype littermates (Figure 4), the biological significance of which is unclear. Surprisingly, there was no evidence of loss of the remaining p 53 allele in the tumors, which was further corroborated by retention of the remaining p53 allele and absence of p53 mutation in cell lines derived from the tumors (data not shown).

Sulindac reduces dysplasia in $\mathrm{L} 2 \mathrm{D1}^{+} / \mathrm{p}^{53^{+/}-}$mice. Sulindac is a common chemopreventive agent employed frequently in mouse models of different cancers. We tested its potential utility in $\mathrm{L} 2 \mathrm{D} 1^{+} / \mathrm{p} 53^{+/-}$mice (which were selected for their longer survival compared with $\mathrm{L} 2 \mathrm{D} 1^{+} / \mathrm{p} 53^{-/-}$mice). Sulindac was added to the drinking water of $\mathrm{L} 2 \mathrm{D} 1^{+} / \mathrm{p} 53^{+/-}$and wild-type control mice; there was a statistically significant reduction in the mean dysplasia scores in $\mathrm{L} 2 \mathrm{D} 1^{+} / \mathrm{p} 53^{+/-}$mice compared with untreated $\mathrm{L} 2 \mathrm{D} 1^{+} / \mathrm{p} 53^{+/-}$mice (Figure $5 \mathrm{a}$ ). $\mathrm{L} 2 \mathrm{D} 1^{+} / \mathrm{p} 53^{+/}$with sulindac treatment significant $(\mathrm{P}<0.05)$ compared with $\mathrm{L} 2 \mathrm{D} 1^{+} / \mathrm{p} 53^{+/-}$untreated. While we appreciate that the mechanisms underlying

\section{Figure 5}

Sulindac (400 ppm) was administered in the drinking water on a daily basis for 3 months to L2D $1^{+/ p} 53^{+/-}$mice $(n=8)$ and wild-type littermate mice $(n=8)$, starting when mice were 4 months old. (a) Dysplasia scores were calculated after the mice were sacrificed at the age of 8 months. UE, upper esophagus; LE, lower esophagus. Micrographs show immunohistochemical staining for COX-2 in the esophagus ( $\mathbf{b}$ and $\mathbf{c}$ ) and prostaglandin receptor EP2 in the tongue ( $\mathbf{d}$ and $\mathbf{e}$ ) in sulindac-treated ( $\mathbf{c}$ and $\mathbf{e}$ ) and -untreated (b and $\mathbf{d}$ ) $\mathrm{L} 2 \mathrm{D} 1^{+/} / \mathrm{p} 53^{+/-}$mice, respectively. Magnification $\times 400$. sulindac's effects are several, including COX-2-dependent and COX-2-independent actions, our main goal initially was to establish the feasibility of applying a chemopreventive agent in the context of our genetic mouse model. Nevertheless, we analyzed the expression of COX-2 and prostaglandin EP2 receptor (a major target of COX-2) in sulindac-treated and -untreated $\mathrm{L} 2 \mathrm{D} 1^{+} / \mathrm{p} 53^{+/-}$mice. COX 2 expression and EP2 receptor expression were reduced by about $50 \%$ in the squamous epithelium of treated $\mathrm{L} 2 \mathrm{D} 1^{+} / \mathrm{p} 53^{+/-}$mice compared with untreated $\mathrm{L} 2 \mathrm{D} 1^{+} / \mathrm{p} 53^{+/-}$mice.
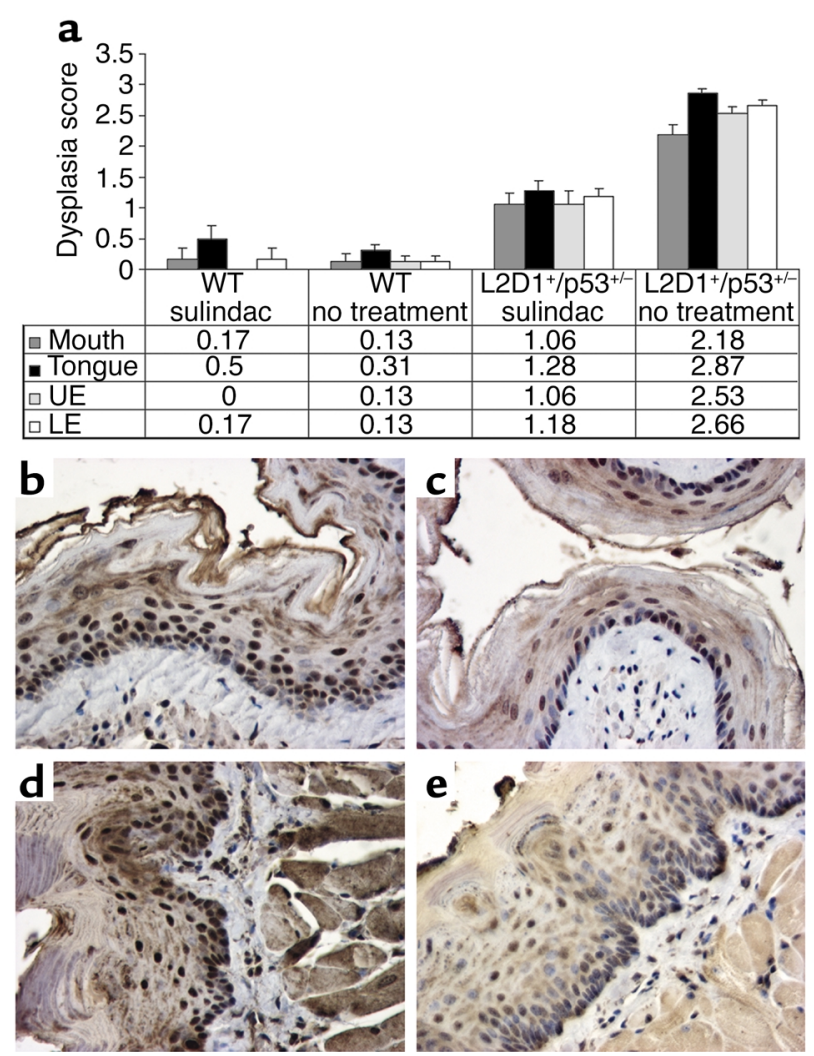


\section{Table 4}

Tumor occurrence in athymic nude mice from oral epithelial cell lines derived from different mouse genotypes

\begin{tabular}{|c|c|c|c|}
\hline $\begin{array}{l}\text { Injected cell } \\
\text { genotype }\end{array}$ & Tumors & $\begin{array}{l}\text { Average tumor } \\
\text { volume }(\mathrm{ml})\end{array}$ & Histology \\
\hline Wild-type & $0 / 4$ & ND & ND \\
\hline $\mathrm{L}^{2} \mathrm{D} 1^{+} / \mathrm{p} 53^{+/+}$ & $0 / 4$ & ND & ND \\
\hline $\mathrm{p} 53^{+/-}$ & $0 / 6$ & ND & ND \\
\hline $\mathrm{p} 53^{-/-}$ & $0 / 4$ & ND & ND \\
\hline $\mathrm{L}^{2} \mathrm{D} 1^{+} / \mathrm{p} 53^{+/-}$ & $5 / 6$ & 11.0 & PDSC with spindle cells \\
\hline $\mathrm{L} 2 \mathrm{D} 1^{+/} / \mathrm{p} 53^{-/-}$ & $3 / 4$ & 40.8 & PDSC with spindle cells \\
\hline
\end{tabular}

ND, no tumor detected; PDSCC, poorly differentiated squamous cell carcinoma.

Cell lines from $\mathrm{L} 2 \mathrm{D} 1^{+} / \mathrm{p} 53^{+/-}$and $\mathrm{L} 2 \mathrm{D} 1^{+} / \mathrm{p} 53^{-/-}$mice form tumors in nude mice. Since the tongue was most affected by cancer, we further tested the biological properties of the dysplastic and cancerous oral cells. Accordingly, cell lines were derived from tongue epithelia of mice (aged 4-5 months) from all genotypes. Their epithelial or keratinocyte origin was confirmed by the expected expression of keratin markers (keratin 5 and keratin 14 in basal cells and keratin 4 and keratin 13 in suprabasal cells) and E-cadherin (data not shown). Early passage cells corresponding to the different genotypes were injected into athymic nude mice, and tumors arose only from oral keratinocytes derived from

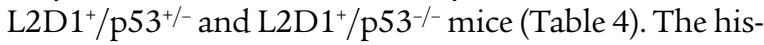
tology of these tumors corresponded to poorly differentiated squamous cell cancers mixed with spindle cells (Figure 6), as further confirmed by cytokeratin, desmin, and S-100 immunohistochemistry (Figure 6).

\section{Discussion}

We describe a novel genetic mouse model of oralesophageal squamous cell cancer that provides new insights into underlying molecular mechanisms and follows the histopathological and genetic changes observed in the human counterpart. Tissue- and cell type-specific cyclin D1 expression leads to dysplasia (a precursor of cancer) in the oral-esophageal squamous epithelium, and combination with p53 inactivation resulted in cancer. Cyclin D1 expression in other cell types such as lymphocytes, skin keratinocytes, or myocytes leads to increased proliferation and/or premalignant lesions, but is generally not sufficient for the development of overt cancer (23-26). An exception is in mammary epithelial cells (27), where cyclin D1 seems to play a particularly prominent role $(28,29)$. Cooperation by cyclin D1 with other genetic alterations is essential for tumor formation in mouse models. Thus, cyclin D1 and c-myc induce lymphomas, and cyclin D1 and ras generate skin tumors in mice $(23,24,30,31)$.

Direct cooperation between the cyclin $\mathrm{D} 1 / \mathrm{pRb}$ and p53 pathways is observed in our mouse model. Here we show that cyclin D1 expression and p53 inactivation cooperate to induce a rapid progression of dysplasia and cancer specific to oral-esophageal squamous epithelial cells in mice. Interestingly, the frequency of induced tumors was higher in the oral cavity than in the esophagus. This difference may be due in part to the higher expression of p63 (a p53 ortholog) in the esophagus than the oral cavity, thereby permitting the activation of antiproliferative and antiapoptotic genes such as p21 and bax (32).

This model allows the determination of specific genetic events in multistep tumorigenesis, and has significant applications in chemoprevention and therapeutics as well. When the $\mathrm{L} 2 \mathrm{D} 1^{+} / \mathrm{p} 53^{+/-}$mice were treated with sulindac, a nonsteroidal anti-inflammatory agent with chemopreventive properties, progression to severe dysplasia was markedly diminished.

Because the cooperation of cyclin D1 expression and p53 deficiency leads to malignant transformation, we developed novel epithelial cell lines from the tongues of all mouse genotypes, a model that we believe offers physiological advantages over mouse embryonic fibroblasts. Early passage cell lines derived from the tongues of $\mathrm{L} 2 \mathrm{D} 1^{+} / \mathrm{p} 53^{+/-}$and $\mathrm{L} 2 \mathrm{D} 1^{+} / \mathrm{p} 53^{-/-}$mice, but not control mice, resulted in tumors in athymic nude mice. The tumors were poorly differentiated squamous cell cancers with spindle-like and mesenchymal components. Results of immunohistochemical and electron microscopic studies strongly suggest that spindle cells arise via metaplasia of malignant squamous cells $(33,34)$, consistent with our findings. Interestingly, this squamous epithelial-mesenchymal transition may reflect an aggressive tumor. Based on preliminary gene array results of the nude mouse tumors induced from the $\mathrm{L} 2 \mathrm{D} 1^{+} / \mathrm{p} 53^{-/-}$oral cell line,
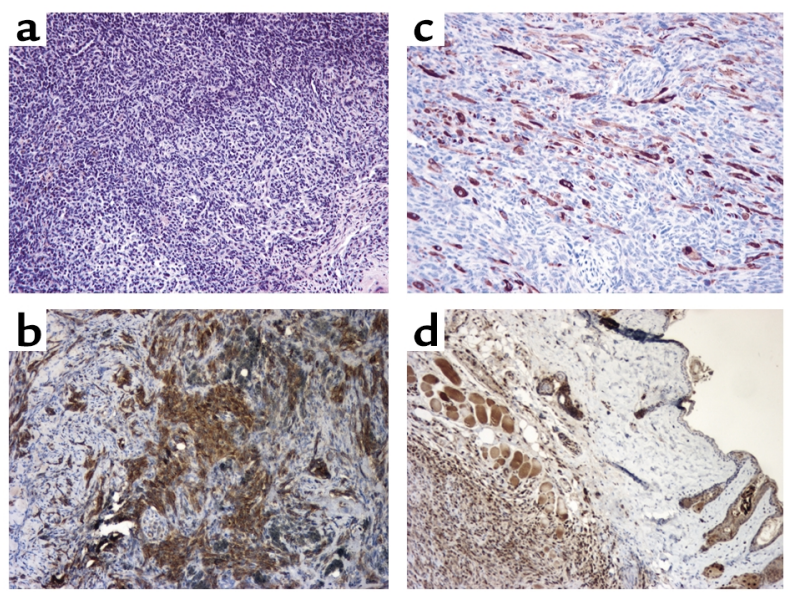

Figure 6

Oral epithelial cell lines were established in culture from $\mathrm{L} 2 \mathrm{D} 1^{+} / \mathrm{p} 53^{+/-}$ and $\mathrm{L} 2 \mathrm{D} 1^{+} / \mathrm{p} 53^{-/-}$mice and all control groups. These were then injected into athymic nude mice and monitored for up to 3 months for tumor development. Tumors contain histologic features of poorly differentiated squamous cell cancer mixed with spindle cells. Depicted are representative photomicrographs of nude mouse tumors from cell lines derived from L2D1 $/ \mathrm{p} 53^{+/-}$mice. (a) Hematoxylin and eosin staining. (b) Pancytokeratin immunohistochemical staining. (c) Desmin immunohistochemical staining. (d) S-100 immunohistochemical staining. Magnification, $\times 400$. 
we have found upregulation of snail, which is known to downregulate E-cadherin; induction of epiregulin, which is an autocrine growth factor in squamous epithelial cells; and downregulation of maspin, a protease inhibitor (Harada and Rustgi, unpublished observations). Loss of maspin is associated with poor prognosis in oral squamous cell cancer (35).

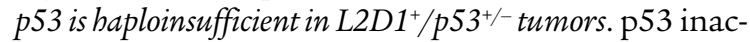
tivation by itself is uncommonly associated with epithelial tumors in mice $(20,21)$. However, a recent study demonstrated the occurrence of epithelial cancer in telomerase RNA null (Terc-null), p53-mutant mice, revealing a complex interaction between telomere dynamics, checkpoint responses, and carcinogenesis (36). Differences in telomere biology might be one reason for some of the differences in human and mouse carcinogenesis involving p53 $(37,38)$.

Our model supports the notion that p53 plays an important role in mouse epithelial carcinogenesis. Loss of $\mathrm{p} 53$ function results in genetic instability, thereby leading to changes in chromosome number and ploidy, and further increasing the likelihood that such cells will more rapidly evolve toward malignancy. By contrast, selective inactivation of the remaining p53 allele during epithelial tumor progression in the brains of transgenic mice reveals that there is apoptosis reduction and absence of chromosomal instability (39).

The remaining p53 allele was not lost during the development of invasive oral-esophageal cancer in the $\mathrm{L} 2 \mathrm{D} 1^{+} / \mathrm{p} 53^{+/-}$mice or in the athymic nude mice (data not shown). Besides the possibility of mutations in the remaining p53 allele, it is also conceivable that wildtype p53 is retained in the tumors and reduction of p53 dosage is sufficient to promote cancer formation in mice (40). p53 haploinsufficiency might well explain the induction of malignant transformation in the context of cyclin D1 expression. Haploinsufficiency in tumor suppression is well described in different mouse models. For example, p27kip1, Lkb1, and Dmp1 (a p19ARF transcriptional activator) exert their tumor suppression function in a dose-dependent manner (41-43). p27kip1 heterozygous mice are predisposed to tumorigenesis and do not lose the wild-type allele.

While abrogation of the $\mathrm{pRb}$ and $\mathrm{p} 53$ pathways is necessary for the development of oral-esophageal cancer, it is likely that other genetic alterations may be required, although this does not involve $\mathrm{p} 16^{\mathrm{INK} 4 \mathrm{a}}$ or p19 $19^{\text {RRF }}$ deletion or $\mathrm{p} 16^{\text {INK4a }}$ promoter hypermethylation in our model. Our findings support the notion that cyclin D1 expression alone, without p16 inactivation, can abrogate the $\mathrm{pRb}$ pathway, at least in cancers

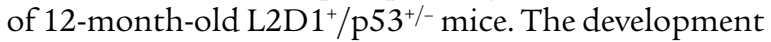
of tumors in $\mathrm{L} 2 \mathrm{D} 1^{+} / \mathrm{p} 53^{+/-}$and $\mathrm{L} 2 \mathrm{D} 1^{+} / \mathrm{p} 53^{-/}$mice does not appear to be a function of cyclin D1 expression levels. Recently, the specific hyperactivity of CDK6 found in human oral cancer cell lines may reflect a unique role for CDK6 in promoting proliferation in these cells that cannot be filled by CDK4 (44). Likewise, p53 loss seems to obviate the need for $\mathrm{p} 19^{\mathrm{ARF}}$ deletion.
We believe our tumor model will serve as an optimal platform for further analysis by genome-wide methods or expression profiling to identify cooperating genes that might have direct relevance to human oral-esophageal cancers.

\section{Acknowledgments}

This work was supported by NIH grant P01 DE-12467 (A.K. Rustgi, R. Kent), the Leonard and Madlyn Abramson Family Cancer Research Institute at the University of Pennsylvania Cancer Center (A.K. Rustgi), the NIH/NIDDK Center for Molecular Studies in Digestive and Liver Diseases (P30 DK-50306) and its Morphology, Molecular Biology, Mouse and Cell Culture Core Facilities, National Cancer Institute grant N01-CN-95031-72, Deutsche Krebshilfe grants D/96/17197 and 10-1656-Op1 (O.G. Opitz), and a Howard Hughes Medical Institute Physician Postdoctoral Fellowship (N.E. Sharpless). We wish to thank Phil Hinds, Karl Munger, David Wong, and Hubert Blum for helpful discussions and support. Additionally, Gita Goessel, Sarah McNally, and Gary Swain provided expert technical assistance. We also wish to thank Randy Todd, Claudia Andl, Kenji Oyama, Camerone Johnstone, and Therese Deramandt.

1. Patel, V., Leethanakul, C., and Gutkind, J.S. 2001. New approaches to the understanding of the molecular basis of oral cancer. Crit. Rev. Oral Biol. Med. 12:55-63.

2. Mandard, A.M., Hainaut, P., and Hollstein, M. 2000. Genetic steps in the development of squamous cell carcinoma of the esophagus. Mutat. Res. 462:335-342.

3. Salley, J.J. 1954. Experimental carcinogenesis in the cheek pouch of the Syrian hamster. J. Dent. Res. 33:253-262.

4. Silberman, S., and Shklar, G. 1963. The effect of carcinogen (DMBA) applied to the hamster's buccal pouch in combination with croton oil. Oral Surg. 16:1344-1365.

5. Siglin, J.C., Khare, L., and Stoner, G.D.1995. Evaluation of dose and treatment duration on the esophageal tumorigenicity of $\mathrm{N}$-nitrosomethylbenzylamine in rats. Carcinogenesis. 16:259-265.

6. Bartkova, J., Lukas, J., Strauss, M., Gusterson, B., and Bartek, J. 1995 Abnormal patterns of D-type cyclin expression and G1 regulation in human head and neck cancer. Cancer Res. 55:949-956.

7. Nakagawa, H., et al. 1995. Human cyclin D1 oncogene and esophageal squamous cell carcinoma. Cancer. 76:541-549.

8. Shamma, A., et al. 2000. Cyclin D1 overexpression in esophageal dysplasia: a possible biomarker for carcinogenesis of esophageal squamous cell carcinoma. Int. J. Oncol. 16:261-266.

9. Bova, R.J., et al. 1999. Cyclin D1 and p16INK4A expression predict reduced survival in carcinoma of the anterior tongue. Clin. Cancer Res. 5:2810-2819.

10. Shinozaki, H., et al. 1996. Cyclin D1 amplification as a new predictive classification for squamous cell carcinoma of the esophagus. Clin. Cancer Res. 2:1155-1161.

11. Bradley, G., et al. 2001. Abnormalities of the ARF-p53 pathway in oral squamous cell carcinoma. Oncogene. 20:654-658.

12. Bennett, W.P., et al. 1992. p53 mutation and protein accumulation during multistage human esophageal carcinogenesis. Cancer Res. 52:6092-6097.

13. Levine, A.J. 1997. p53, the cellular gatekeeper for growth and division. Cell. 88:323-331.

14. Lakin, N.D., and Jackson, S.P. 1999. Regulation of p53 in response to DNA damage. Oncogene. 18:7644-7655.

15. Nakagawa, H., et al. 1997. The targeting of the cyclin D1 oncogene by an Epstein-Barr virus promoter in transgenic mice causes dysplasia in the tongue, esophagus and forestomach. Oncogene. 14:1185-1190.

16. Yan, Y.X., Nakagawa, H., Lee, M.H., and Rustgi, A.K. 1997. Transforming growth factor-alpha enhances cyclin D1 transcription through the binding of early growth response protein to a cis-regulatory element in the cyclin D1 promoter. J. Biol. Chem. 272:33181-33190.

17. Sharpless, N.E., et al. 2001. Impaired nonhomologous end-joining provokes soft tissue sarcomas harboring chromosomal translocations, amplifications, and deletions. Mol. Cell. 6:1187-1196. 
18. Sharpless, N.E., et al. 2001. Loss of p16Ink4a with retention of $\mathrm{p} 19^{\text {Arf }}$ predisposes mice to tumorigenesis. Nature. 413:86-91.

19. Nakagawa, H., Inomoto, T., and Rustgi, A.K. 1997. A CACCC box-like cis-regulatory element of the Epstein-Barr virus ED-L2 promoter interacts with a novel transcriptional factor in tissue-specific squamous epithelia. J. Biol. Chem. 272:16688-16699.

20. Wilhide, C.C., Van Dang, C., Dipersio, J., Kennedy, A.A., and Bray, P.F. 1994. Overexpression of cyclin D1 in the Dami megakaryocytic cell line causes growth arrest. Blood. 86:294-304.

21. Donehower, L.A., et al. 1992. Mice deficient for p53 are developmentally normal but susceptible to spontaneous tumours. Nature. 356:215-221.

22. Jacks, T., et al. 1994. Tumor spectrum analysis in p53-mutant mice. Curr. Biol. 4:1-7.

23. Bodrug, S.E., et al. 1994. Cyclin D1 transgene impedes lymphocyte maturation and collaborates in lymphomagenesis with the myc gene. EMBO J. 13:2124-2130.

24. Lovec, H., Grzeschiczek, A., Kowalski, M.B., and Moroy, T. 1994. Cyclin $\mathrm{D} 1 / \mathrm{bcl}-1$ cooperates with myc genes in the generation of B-cell lymphoma in transgenic mice. EMBOJ. 13:3487-3495.

25. Robles, A.I., et al. 1996. Expression of cyclin D1 in epithelial tissues of transgenic mice results in epidermal hyperproliferation and severe thymic hyperplasia. Proc. Natl. Acad. Sci. USA. 93:7634-7638.

26. Soonpaa, M.H., et al. 1997. Cyclin D1 overexpression promotes cardiomyocyte DNA synthesis and multinucleation in transgenic mice. J. Clin. Invest. 99:2644-2654.

27. Wang, T.C., et al. 1994. Mammary hyperplasia and carcinoma in MMTVcyclin D1 transgenic mice. Nature. 269:669-671.

28. Sicinski, P., et al. 1995. Cyclin D1 provides a link between development and oncogenesis in the retina and breast. Cell. 82:621-630.

29. Fantl, V., Stamp, G., Andrews, A., Rosewell, I., and Dickson, C. 1995. Mice lacking cyclin D1 are small and show defects in eye and mammary gland development. Genes Dev. 9:2364-2372.

30. Robles, A.I., et al. 1998. Reduced skin tumor development in cyclin D1deficient mice highlights the oncogenic ras pathway in vivo. Genes Dev. 12:2469-2474.

31. Rodriguez-Puebla, M.L., Robles, A.I., and Conti, C.J. 1999. ras activity and cyclin D1 expression: an essential mechanism of mouse skin tumor development. Mol. Carcinog. 24:1-6.
32. Suliman, Y., et al. 2001. p63 expression is associated with p53 loss in oral-esophageal epithelia of p53-deficient mice. Cancer Res. 61:6467-6473.

33. Battifora, H. 1976. Spindle cell carcinoma: ultrastructural evidence of squamous origin and collagen production by the tumor cells. Cancer. 37:2275-2282.

34. Zarbo, R.J., Crissman, J.D., Venkat, H., and Weiss, M.A. 1986. Spindlecell carcinoma of the upper aerodigestive tract mucosa. Am. J. Surg. Pathol. 10:741-753.

35. Xia, W., et al. 2000. High tumoral maspin expression is associated with improved survival of patients with oral squamous cell carcinoma. Oncogene. 19:2398-2403.

36. Artandi, S.E., et al. 2000. Telomere dysfunction promotes non-reciprocal translocations and epithelial cancers in mice. Nature. 406:641-645.

37. Chin, L., et al. 1999. p53 deficiency rescues the adverse effects of telomere loss and cooperates with telomere dysfunction to accelerate carcinogenesis. Cell. 97:527-538.

38. Artandi, S.E., and DePinho, R.A. 2000. A critical role for telomeres in suppressing and facilitating carcinogenesis. Curr. Opin. Genet. Dev. 10:39-46.

39. Lu, X., et al. 2001. Selective inactivation of p53 facilitates mouse epithelial tumor progression without chromosomal instability. Mol. Cell. Biol. 21:6017-6030.

40. Venkatachalam, S., et al. 1998. Retention of wild-type p53 in tumors from $\mathrm{p} 53$ heterozygous mice: reduction of $\mathrm{p} 53$ dosage can promote cancer formation. EMBO J. 17:4657-4667.

41. Fero, M.L., Randel, E., Gurley, K.E., Roberts, J.M., and Kemp, C.J. 1998. The murine gene p27Kip1 is haplo-insufficient for tumor suppression. Nature. 396:177-180.

42. Inoue, K., Zindy, F., Randle, D.H., Rehg, J.E., and Sherr, C.J. 2001. Dmp1 is haplo-insufficient for tumor suppression and modifies the frequencies of Arf and p53 mutations in Myc-induced lymphomas. Genes Dev. 15:2934-2939.

43. Miyoshi, H., et al. 2002. Gastrointestinal hamartomatous polyposis in Lkb1 heterozygous knockout mice. Cancer Res. 62:2261-2266.

44. Timmermann, S., Hinds, P., and Münger, K. 1997. Elevated activity of cyclin-dependent kinase 6 in human squamous cell carcinoma lines. Cell Growth Differ. 8:361-370. 